\title{
Electron impact fragmentation of pyrrole molecules studied by fluorescence emission spectroscopy
}

\author{
T.J. Wasowicz, I. Linert, I. Lachowicz, M. Zubek* \\ Department of Physics of Electronic Phenomena, Gdańsk University of Technology, \\ ul. G. Narutowicza 11/12, 80-233 Gdańsk
}

Received May 06, 2011; accepted July 14, 2011; published September 30, 2011

\begin{abstract}
The fluorescence emission spectroscopy using electron impact excitation technique was employed to study fragmentation processes of the gas phase pyrrole molecules. The following excited fragmentation species were observed by detection of their fluorescence decay: the atomic hydrogen $\mathrm{H}(n), n=4-7$ and the diatomic $\mathrm{CH}\left(A^{2} \Delta\right)$, $\mathrm{CN}\left(B^{2} \Sigma^{+}\right), \quad \mathrm{NH}\left(A^{3} \Pi\right)$ and $\mathrm{C}_{2}\left(d^{3} \Pi_{\mathrm{g}}\right)$ fragments. These atomic and molecular products differ from those previously reported in fragmentation of pyrrole and their identification gives a new insight into dissociation and fragmentation channels of the excited states of pyrrole molecules.
\end{abstract}

Interaction of ionizing radiation with biological material in radiodiagnostic examinations or in medical radiotherapy can produce a range of structural and chemical modifications by bond cleavages in the DNA helix. These genotoxic effects are produced by primary radiation and also by generated secondary particles such as electrons and free radicals. Recent experiments in the gas phase on basic DNA building blocks, nucleic acid bases, phosphate group and sugar moiety [1-3] have clearly shown that secondary low energy electrons may lead to bond breaking via resonant dissociative electron attachment and further cause single and double strands breaks in DNA. Also, chemically active secondary radicals created in dissociation, because of their extremely high reactivity, can trigger reactions leading to the damage of the DNA helix. It is therefore important to fully characterize the mechanisms by which different types of radiation, through energy deposition, damage DNA.

Heteroaromatic compounds containing nitrogen play a major role in many different fields of chemistry, biology and medicine, ranging from organic synthesis to molecular genetics. In recent years, much attention has been paid to the study of non-radiative deactivation processes of the excited states of five-membered heteroaromatic molecules, e.g. imidazole, isoxazole and pyrrole [4, 5]. These excited states have, in general, repulsive potential energy curves along one of the stretching coordinates and usually decay by fission of one of the bonds. This fragmentation process is one of the most efficient decay channels [4].

\footnotetext{
*E-mail: mazub@mif.pg.gda.pl
}

The pyrrole molecule $\left(\mathrm{C}_{4} \mathrm{H}_{4} \mathrm{NH}\right)$ belongs to a series of five-membered heterocyclic compounds. Its structure incorporates one nitrogen atom (see Fig. 1) and the molecule is classified in the $C_{2 v}$ symmetry point group. The pyrrole molecule serves as a model system for which photochemical dynamics can be studied in detail. In addition, it is a building block of many biologically important compounds and studies of its interaction with electrons are crucial for understanding of radiation damage in biological tissue [1].

There is a limited amount of work performed on the dissociation and fragmentation processes of pyrrole in the gas phase. The decomposition of pyrrole was studied in the past by Lifshitz et al. [6] and by Mackie et al. [7], who used the single-pulse shock tube technique, in temperature ranges of $1050-1450 \mathrm{~K}$ and $1200-1700 \mathrm{~K}$, respectively. They showed that major products of pyrrole pyrolysis are open ring isomers of pyrrole, cis-, trans-crotonitrile $\left(\mathrm{CH}_{3} \mathrm{CH}=\mathrm{CHCN}\right)$ and allyl cyanide $\left(\mathrm{CH}_{2}=\mathrm{CHCH}_{2} \mathrm{CN}\right)$, together with $\mathrm{HCN}+\mathrm{C}_{3} \mathrm{H}_{4}$ molecules. Although Lifshitz et al. [6] and Mackie et al. [7] obtained very similar products of pyrolysis, they proposed different mechanisms leading to their production. Lifshitz et al. [6] proposed that these isomers were formed via mechanism based on the $\mathrm{N}(1)-\mathrm{C}(5)$ bond cleavage and the hydrogen atoms transfers from the $\mathrm{N}(1)$ and $\mathrm{C}(2)$ atoms to the $\mathrm{C}(5)$ atom, yielding cis-crotonitrile or alternatively the hydrogen atoms transfers from the $\mathrm{N}(1)$ and $\mathrm{C}(5)$ atoms to the $\mathrm{C}(2)$ and $\mathrm{C}(4)$ atoms, respectively, giving allyl cyanide.

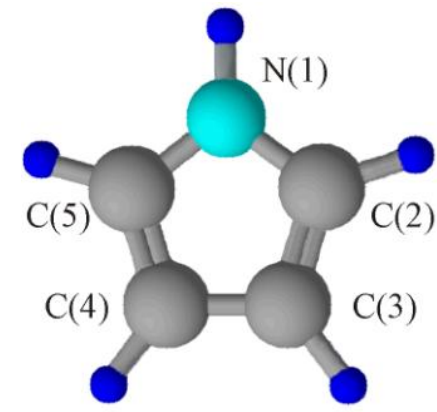

Fig. 1. Schematic diagram of a pyrrole $\left(\mathrm{C}_{4} \mathrm{H}_{4} \mathrm{NH}\right)$ molecule showing the labeling of atoms, carbon atoms are gray, nitrogen atom is cyan and hydrogen atoms are dark blue.

Mackie et al. [7] proposed that the first step of pyrrole 
pyrolysis is the hydrogen atom migration from the $\mathrm{N}(1)$ to $\mathrm{C}(2)$ atom to form pyrrolenine, which is followed by N(1)-C(5) bond scission. Soon after, Lifshitz et al. [8], Zhai et al. [9] and Mackie et al. [10] independently carried out detailed theoretical investigations of isomerization and decomposition channels of pyrrole. All these calculations supported the idea that the initial step of pyrrole pyrolysis is fast transition from pyrrole to pyrrolenine. Later, Blank et al. [11] investigated the photodissociation of pyrrole at $193 \mathrm{~nm}$ and $248 \mathrm{~nm}$, using photofragment translational spectroscopy. They observed reactions leading to the following products: $\mathrm{H}+$ pyrrolyl radical, $\mathrm{HCN}+$ vinylmethylene (or + cyclopropene) and $\mathrm{NH}+\mathrm{CHCCHCH}_{2}$. Recently, Lippert et al. [12], using a two-color pump-probe technique applying femtosecond laser pulses and resonance-enhanced multiphoton ionization technique, have studied the production of $\mathrm{H}$ atoms from the photodissociation of a pyrrole molecule. These investigations have shown that the deactivation of photoexcited pyrrole to the ground state occurs on a very short time scale [12], implying that the internal conversion processes play crucial roles in the deactivation of pyrrole. It involves hydrogen atom detachment, which is the main dissociation channel after excitation into both the lowest dissociative ${ }^{1} \pi \sigma^{*}$ and bound ${ }^{1} \pi \pi^{*}$ states. The production of $\mathrm{H}$ atoms from the ${ }^{1} \pi \sigma^{*}$ state is due to direct adiabatic $\mathrm{N}-\mathrm{H}$ bond cleavage and to ultrafast internal conversion from the ${ }^{1} \pi \sigma^{*}$ excited state to the ground state through conical intersection with subsequent unimolecular dissociation [1, 2]. A new deactivation mechanism based on the out-ofplane ring deformation which directly couples the ${ }^{1} \pi \pi^{*}$ and the ground states has been also proposed [3]. This mechanism should create slow $\mathrm{H}$ atoms and, additionally, via ring opening mechanism, $\mathrm{HCN}$ and $\mathrm{CH}_{2} \mathrm{~N}$ fragments.

The goal of this work was to provide a further insight into the deactivation mechanisms of the gas phase excited pyrrole, which results in the formation of excited neutral atomic and molecular fragments. The applied electron impact optical excitation technique allowed identification of dissociation and fragmentation products by detection of their fluorescence decay. The following fragmentation species were observed: the excited atomic hydrogen $\mathrm{H}(n)$, $n=4-7$ and excited diatomic $\mathrm{CH}\left(A^{2} \Delta\right), \quad \mathrm{CN}\left(B^{2} \Sigma^{+}\right)$, $\mathrm{NH}\left(A^{3} \Pi\right)$ and $\mathrm{C}_{2}\left(d^{3} \Pi_{\mathrm{g}}\right)$ fragments. These atomic and molecular products differ from those reported previously in pyrrole. Their identification gives new results on the dissociation and fragmentation channels of the excited states of pyrrole.

The measurements were performed using an optical excitation electron spectrometer, shown schematically in Fig. 2, which was described in detail previously [13, 14]. Briefly, electrons emitted by a tungsten filament were collimated into a beam by a trochoidal selector with a set of adjacent aperture electrodes.

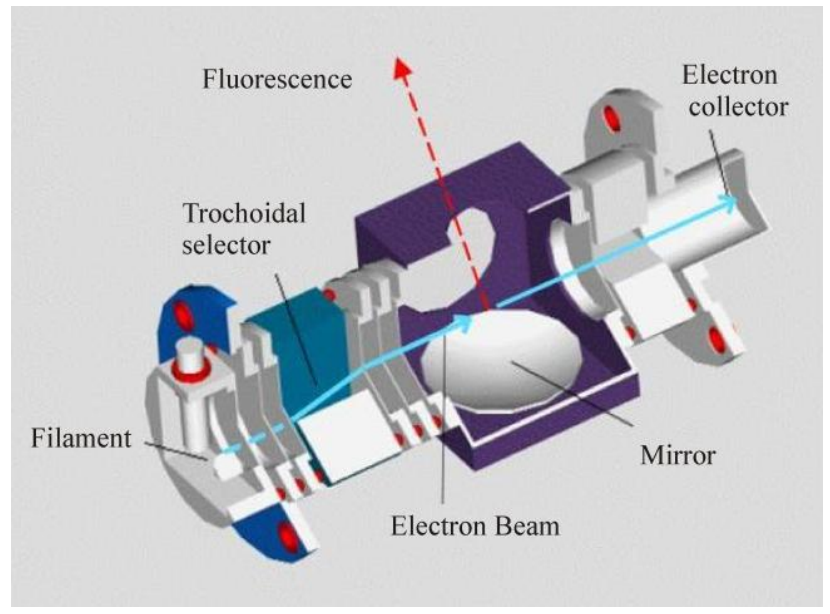

Fig. 2. Schematic diagram of the electron impact optical excitation spectrometer.

The electron beam was directed along the spectrometer by a magnetic field of 60-80Gauss produced by two coils. The electron beam, after leaving the collision region was monitored by a collector. Its intensity was between 1$2 \mu \mathrm{A}$. The energy spread of the beam was estimated to be about 400meV (FWHM). Fluorescence emitted from the collision region passed through a quartz optical lightguide and was focused on the entrance slit of the $0.25 \mathrm{~m}$ Ebert monochromator which was equipped with a grating having 1181 lines $/ \mathrm{mm}$. The dispersed fluorescence was recorded by a cooled photomultiplier.

The fluorescence spectrum measured in pyrrole at an electron energy of $70 \mathrm{eV}$ and in a wavelength range of $300-495 \mathrm{~nm}$ is shown in Fig. 3. In this measurement the optical resolution $(\Delta \lambda / \lambda)$ was about 0.005 . The wavelength scale was calibrated to within $\pm 0.2 \mathrm{~nm}$ in nitrogen against the position of the $(0,0)$ line of the second positive band at $337 \mathrm{~nm}$.

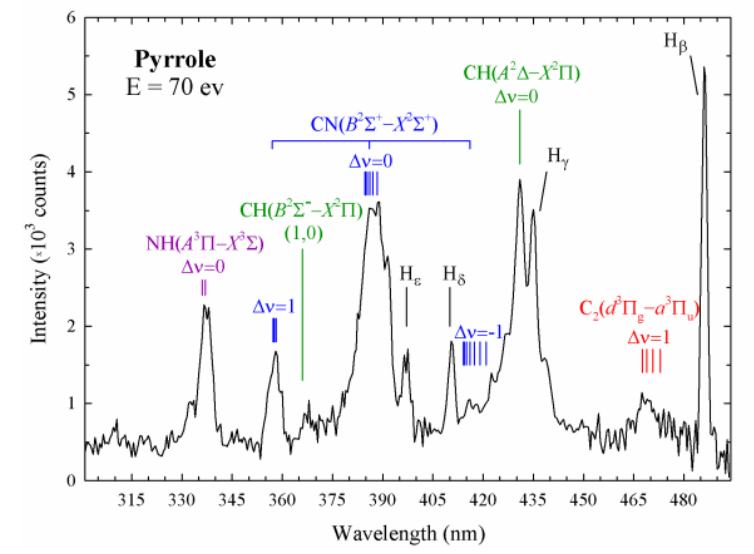

Fig. 3. Emission spectrum obtained in pyrrole at an incident electron energy $\mathrm{E}=70 \mathrm{eV}$. The spectrum was corrected for the wavelength dependence of the sensitivity of the optical detection system.

The recorded spectra were corrected for the wavelength variation of sensitivity of the optical detection channel. 
Electron energy was calibrated in a mixture of pyrrole and nitrogen against the position of the excitation threshold of the $337 \mathrm{~nm}$ line at $11.03 \mathrm{eV}$.

The prominent features of the spectrum are the molecular $\quad \mathrm{A}^{3} \Pi \rightarrow \mathrm{X}^{3} \Sigma, \quad \mathrm{B}^{2} \Sigma^{+} \rightarrow \mathrm{X}^{2} \Sigma^{+} \quad$ and $\quad \mathrm{A}^{2} \Delta \rightarrow \mathrm{X}^{2} \Pi_{\mathrm{r}}$ emission bands of the excited $\mathrm{NH}\left(\mathrm{A}^{3} \Pi\right), \mathrm{CN}\left(\mathrm{B}^{2} \Sigma^{+}\right)$and $\mathrm{CH}\left(\mathrm{A}^{2} \Delta\right)$ fragments, respectively. The $\mathrm{NH}\left(\mathrm{A}^{3} \Pi \rightarrow \mathrm{X}^{3} \Sigma\right)$ band consists of two overlapping vibrational transitions $(0,0)$ and $(1,1)$, at $336 \mathrm{~nm}$ and $337 \mathrm{~nm}$, respectively. The $\mathrm{CN}$ emission bands (the Violet system) appear in the regions between $375-390 \mathrm{~nm}(\Delta \mathrm{v}=0), 355-365 \mathrm{~nm}(\Delta \mathrm{v}=1)$ and $415-425 \mathrm{~nm}(\Delta \mathrm{v}=-1)$. They indicate vibrational, $\mathrm{v}=0-4$ and rotational excitation of the $\mathrm{CN}$ fragments. The $\mathrm{CH}\left(\mathrm{A}^{2} \Delta \rightarrow \mathrm{X}^{2} \Pi_{\mathrm{r}}\right)$ bands extend from $413 \mathrm{~nm}$ to $445 \mathrm{~nm}$. The shape of the $\mathrm{CH}$ profile arises from the overlapping series of rotational lines of the $(0,0),(1,1)$ and $(2,2)$ vibrational transitions. The maximum at $430 \mathrm{~nm}$ corresponds to overlapping $\mathrm{Q}$ branches of the $(0,0)$ and $(1,1)$ vibrational transitions. The increased width at the base of the peak indicates high rotational excitation of the $\mathrm{CH}$ fragments. The $\mathrm{P}$ branches of the vibrational transitions produce a structure above $433 \mathrm{~nm}$, which is partly obscured by the $\mathrm{H}_{\gamma}$ line. Two much weaker molecular bands are also seen in Fig. 3. The first observed near $367 \mathrm{~nm}$ is due to the $\mathrm{CH}(1,0)$ vibrational transition of the $B^{2} \Sigma^{-} \rightarrow X^{2} \Pi_{\mathrm{r}}$ band. The second is due to the vibrationally excited $\mathrm{C}_{2}\left(\mathrm{~d}^{3} \Pi_{\mathrm{g}}\right) \quad\left(\mathrm{d}^{3} \Pi_{\mathrm{g}} \rightarrow \mathrm{a}^{3} \Pi_{\mathrm{u}}\right)$ band (the Swan system) and is detected near $468 \mathrm{~nm}$. Furthermore, the fluorescence spectrum of Fig. 3 contains four atomic lines of the Balmer series, $\mathrm{H}_{\beta}$ through to $\mathrm{H}_{\varepsilon}$ occurring by decay of the hydrogen $\mathrm{H}(n)$ atom from the $n=4-7$ states.

A simple fragmentation process in the excited pyrrole molecule is expected in the production of atomic hydrogen $\mathrm{H}(n=4-7)$ fragments. These may directly result from the abstraction of $\mathrm{H}$ atoms from the pyrrole ring (Fig. 1):

$$
\mathrm{C}_{4} \mathrm{H}_{4} \mathrm{NH}^{*} \rightarrow \mathrm{C}_{4} \mathrm{H}_{4} \mathrm{~N}+\mathrm{H}(n) .
$$

The estimated dissociation energy limit of this process for $\mathrm{H}(n=4)$ is $16.77 \mathrm{eV}$, which is obtained from the $\mathrm{N}-\mathrm{H}$ bond strength of $4.02 \pm 0.04 \mathrm{eV}$ [15] and the excitation energy of $\mathrm{H}(n=4)$ state of $12.75 \mathrm{eV} . \mathrm{H}$ atoms can also be abstracted from $\mathrm{C}$ atoms, however the $\mathrm{C}-\mathrm{H}$ bond strength is higher than that for $\mathrm{N}-\mathrm{H}$ by about $1.2 \mathrm{eV}[16]$.

Formation of the $\mathrm{NH}$ fragment obviously requires opening the ring of the pyrrole molecule by $\mathrm{N}(1)-\mathrm{C}(2)$ (or $\mathrm{N}(1)-\mathrm{C}(5)$ ) bond cleavage and next, before other competing processes occur, breakage of the single bond between $\mathrm{N}(1)-\mathrm{C}(5)$ (or $\mathrm{N}(1)-\mathrm{C}(2)$ ) atoms, accompanied by $\mathrm{H}$ atom migration between $\mathrm{C}(3)$ and $\mathrm{C}(5)$ atoms (or $\mathrm{C}(4)$ and $\mathrm{C}(2))$. This reaction may follow:

$$
\mathrm{C}_{4} \mathrm{H}_{4} \mathrm{NH}^{*} \rightarrow \mathrm{CH}_{2}=\mathrm{CH}-\mathrm{C} \equiv \mathrm{CH}+\mathrm{NH} \text {. }
$$

The process leading to the formation of $\mathrm{CN}$ fragments is more complex and consists of several stages. At the first stage it requires opening the ring of the pyrrole molecule by $\mathrm{N}(1)-\mathrm{C}(2)$ (or $\mathrm{N}(1)-\mathrm{C}(5)$ ) bond cleavage and hydrogen atoms transfers from the $\mathrm{N}(1)$ and $\mathrm{C}(5)$ atoms to the $\mathrm{C}(2)$ atom. This leads to the developement of cis- or trans-crotonitrile $\left(\mathrm{CH}_{3} \mathrm{CH}=\mathrm{CHCN}\right)$ pyrrole isomers. On the other hand, if hydrogen atoms are transferred from the $\mathrm{N}(1)$ and $\mathrm{C}(5)$ atoms to the $\mathrm{C}(2)$ and $\mathrm{C}(4)$ atoms, respectively, then the allyl cyanide $\left(\mathrm{CH}_{2}=\mathrm{CHCH}_{2} \mathrm{CN}\right)$ isomer will be formed. Now $\mathrm{C}(5)-\mathrm{C}(4)$ bound cleavage proceeds to abstraction of the $\mathrm{CN}$ fragment, which requires $4.72 \pm 0.04 \mathrm{eV}$ [17].

The $\mathrm{CN}$ fragment could also be obtained through the reaction

$$
\mathrm{C}_{4} \mathrm{H}_{4} \mathrm{NH}^{*} \rightarrow \mathrm{CH}_{3} \mathrm{C} \equiv \mathrm{CH}+\mathrm{HCN},
$$

where the $\mathrm{HCN}$ molecule decomposes to $\mathrm{H}+\mathrm{CN}$, which needs further $5.478 \pm 0.009 \mathrm{eV}$ [17].

Finally, the formation of the $\mathrm{CH}$ fragment may start by opening the ring of the pyrrole molecule by, for example, $\mathrm{N}(1)-\mathrm{C}(2)$ bond rapture requiring $5.28 \mathrm{eV}$ [18], which will be followed by the $\mathrm{C}(2)-\mathrm{C}(3)$ double bound cleavage (7.16 $\pm 0.04 \mathrm{eV} \mathrm{[17])} \mathrm{giving}$

$$
\mathrm{C}_{4} \mathrm{H}_{4} \mathrm{NH}^{*} \rightarrow \mathrm{C}_{3} \mathrm{H}_{3} \mathrm{NH}+\mathrm{CH} \text {. }
$$

The work was carried out within COST Action CM0601 "Electron Controlled Chemical Lithography". It was supported by the Polish Ministry for Science and Higher Education under contract 553/N-COST/2009/0.

\section{References}

[1] L. Sanche, Eur. Phys. J. D 35, 367 (2005).

[2] G. Hanel et al., Phys. Rev. Lett. 90, 188104 (2003).

[3] H. Abdoul-Carime, S. Gohlke, E. Illenberger, Phys. Rev. Lett. 92, 168103 (2004)

[4] A.L. Sobolewski, W. Domcke, C. Dedonder-Lardeux, C. Jouvet, Phys. Chem. Chem. Phys. 4, 1093 (2002).

[5] M.N.R. Ashfold et al., Phys. Chem. Chem. Phys. 12, 1218 (2010).

[6] A. Lifshitz, C. Tamburu, A. Suslensky, J. Phys. Chem. 93, 5802 (1989).

[7] J.C. Mackie, M.B. Colket III, P.F. Nelson, M. Esler, Int. J. Chem. Kinet. 23, 733 (1991).

[8] F. Dubnikova, A. Lifshitz, J. Phys. Chem. A 102, 10880 (1998).

[9] L. Zhai, X. Zhou, R. Liu, J. Phys. Chem. A 103, 3917 (1999).

[10] M. Martoprawiro, G.B. Bacskay, J.C. Mackie, J. Phys. Chem. A 103, 3923 (1999).

[11] D.A. Blank, S.W. North, Y.T. Lee, Chem. Phys, 187, 35 (1994).

[12] H. Lippert, H.H. Ritze, I.V. Hertel, W. Radloff, Chem. Phys. Chem. 5, 1423 (2004).

[13] M. Dampc, M. Zubek, Int. J. Mass Spectrom. 277, 52 (2008).

[14] I. Linert, I. Lachowicz, T.J. Wasowicz, M. Zubek, Chem. Phys. Lett. 498, 27 (2010)

[15] J. Wei, A. Kuczmann, J. Riedel, F. Renth, F. Temps, Phys. Chem. Chem. Phys. 5, 315 (2003).

[16] G. da Silva, E.E. Moore, J.W. Bozzelli, J. Phys. Chem. A 110, 13979 (2006).

[17] S.J. Blanksby, G.B. Ellison, Acc. Chem. Res. 36, 255 (2003).

[18] D.R. Lide, Handbook of Chemistry and Physics (CRC Press, Boca Raton 2004). 